\title{
Family planning policy, program, and practice decisionmaking: The role of research evidence and other factors
}

\author{
Karen Hardee \\ Population Council \\ Kelsey Wright \\ Population Council \\ Joanne Spicehandler
}

Follow this and additional works at: https://knowledgecommons.popcouncil.org/departments_sbsr-rh

Part of the Demography, Population, and Ecology Commons, Family, Life Course, and Society Commons, and the International Public Health Commons How does access to this work benefit you? Let us know!

\section{Recommended Citation}

Hardee, Karen, Kelsey Wright, and Joanne Spicehandler. 2015. "Family planning policy, program, and practice decisionmaking: The role of research evidence and other factors." Washington, DC: Population Council, The Evidence Project. 


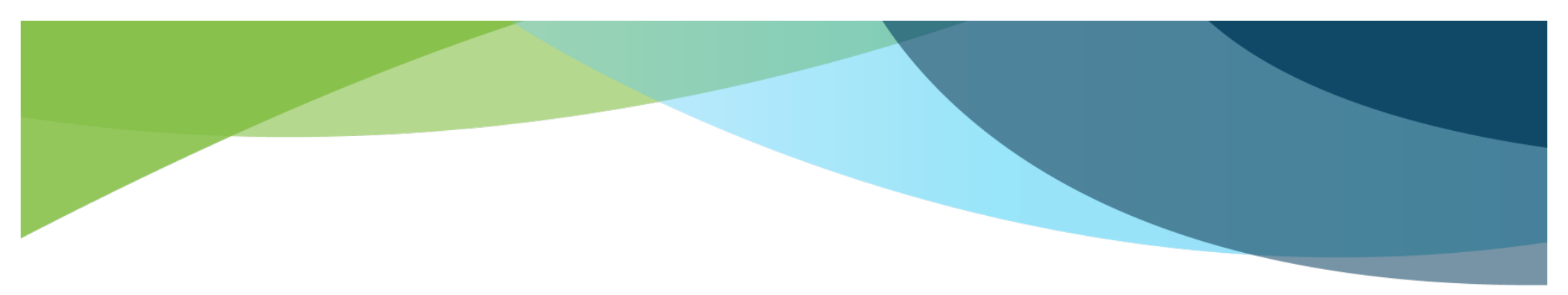

Family Planning Policy, Program, and Practice Decision-making: The Role of Research Evidence and Other Factors

Karen Hardee Kelsey Wright Joanne Spicehandler

September 2015

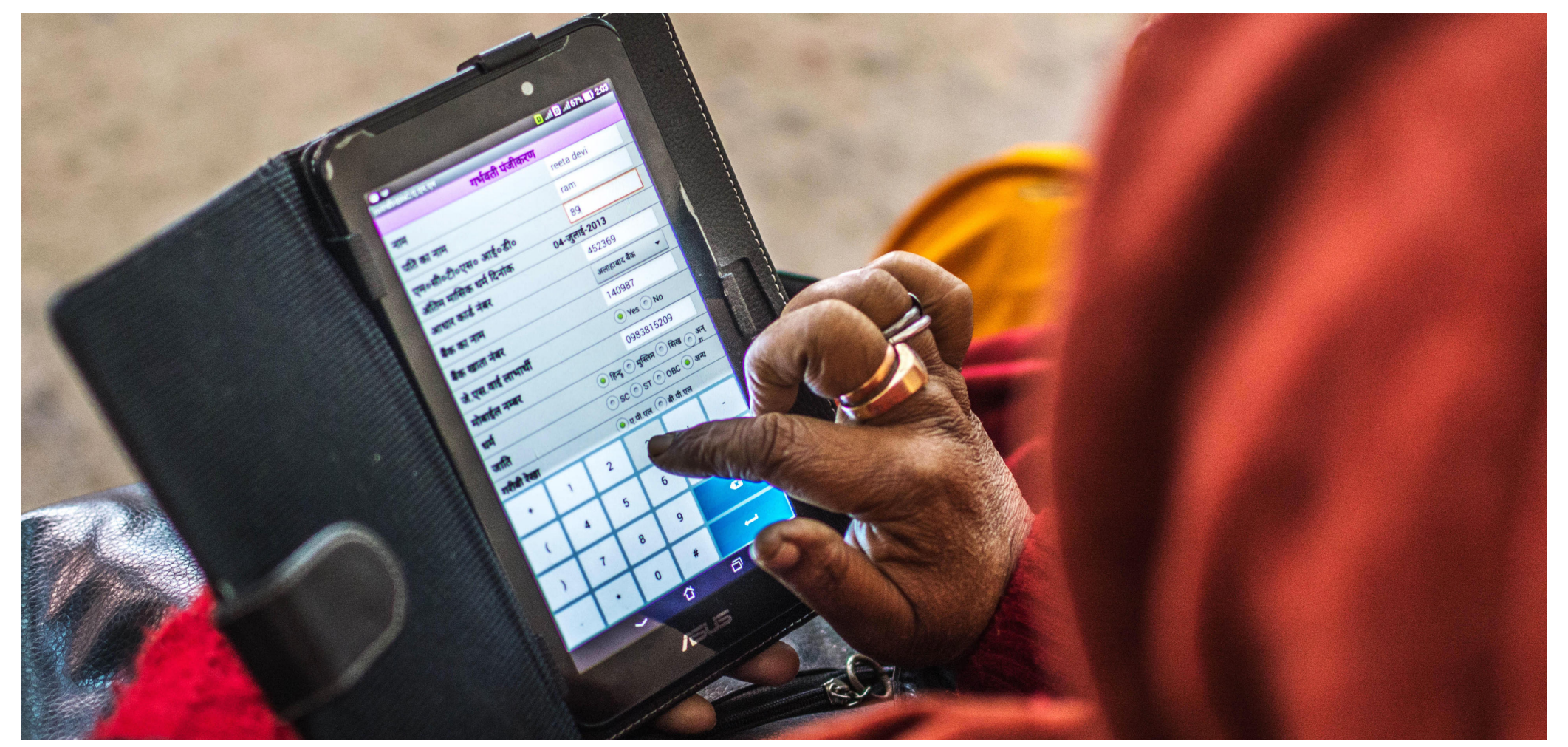





\section{Family Planning Policy, Program, and Practice Decision-making: The Role of Research Evidence and Other Factors}

Karen Hardee, Director, the Evidence Project/Population Council Kelsey Wright, Staff Associate, the Evidence Project/Population Council Joanne Spicehandler, Consultant 


\section{The Evidence Project}

Population Council

4301 Connecticut Avenue, NW, Suite 280

Washington, DC 20008 USA

tel +12022379400

evidenceproject.popcouncil.org

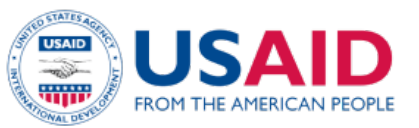

The Evidence Project is made possible by the generous support of the American people through the United States Agency for International Development (USAID) under the terms of cooperative agreement no. AID-

OAA-A-13-00087. The contents of this document are the sole responsibility of the Evidence Project and Population Council and do not necessarily reflect the views of USAID or the United States Government.

\section{Evidence}

The Evidence Project uses implementation science-the strategic generation, translation, and use of evidence - to strengthen and scale up family planning and reproductive health programs to reduce unintended pregnancies worldwide. The Evidence Project is led by the Population Council in partnership with INDEPTH Network, International Planned Parenthood Federation, Management Sciences for Health, PATH, Population Reference Bureau, and a University Research Network.

Published in September 2015.

Suggested citation: Hardee, Karen, Kelsey Wright, and Joanne Spicehandler. 2015. "Family Planning Policy, Program, and Practice Decision-making: The Role of Research Evidence and Other Factors," Working Paper. Washington, DC: Population Council, The Evidence Project.

Photo credit on cover page (C) 2015 Girdhari Bora for IntraHealth International, Courtesy of Photoshare.

(C) 2015 The Population Council, Inc. 


\section{Table of Contents}

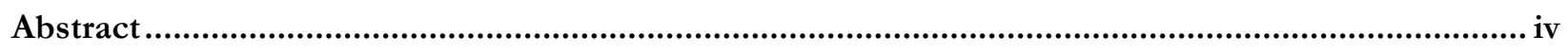

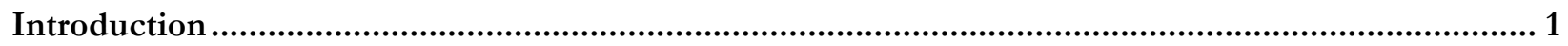

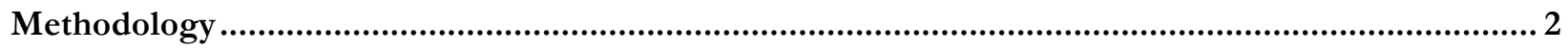

Researchers' and Decision-makers' Views of 'Evidence' ..............................................................................

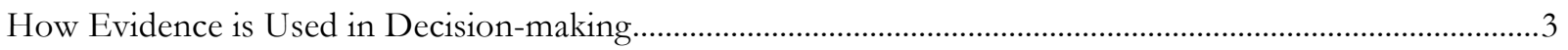

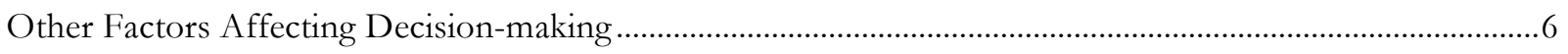

Examples from Family Planning of Other Factors Influencing Decision-making ........................................8

The Importance of Building Evidence Over Time ........................................................................................

Promising Interventions to Expand the Role of Research Evidence in Decision-making.............................11

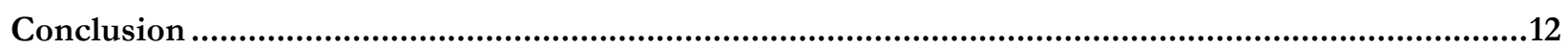

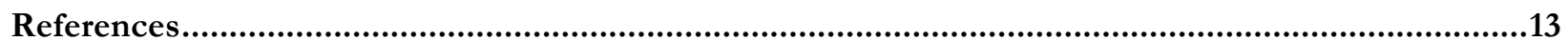




\section{Abstract}

Current attention to increasing access to family planning has increased focus on ensuring that policy, programming and practice are "evidence-based." Given the rich history of research in the family planning field, this paper set out to answer when, what types and how evidence is used in decision-making related to family planning. Views of what constitutes evidence need to be more aligned, with researchers understanding that "evidence-based" does not only mean "research evidence-based" to decision-makers and with decisionmakers understanding the value of robust research evidence among other evidence they consider when making decisions. Decision-makers appreciate research but it is only one factor they take into consideration and may not be the most influential factor in their decision-making. Research findings tend to be filtered through decision-makers' values and beliefs in addition to political, economic and social considerations. Examples from family planning reinforce the persistence of other factors affecting decision-making. A number of promising interventions exist to increase how research evidence, vis a vis other factors, can inform decision-making. Expecting policy or program change from single studies is mostly unrealistic, but examples from decades of family planning programming shown in this paper illustrate the incremental influence of evidence from research on family planning policies and programs. 


\section{Introduction}

Much has been written about evidence-based medicine (EBM), evidence-based policy (EBP) and evidenceinformed decision-making (EIDM) - all of which are intended to provide legitimacy to policy, program and practice decisions via an objective and scientific process (Klein 2000; Bowen and Zwi2005; Lewi 2007; Brownson et al. 2009; Dopson 2010; Yamey and Feachem 2011). The importance of using evidence in policy and program development and implementation is clear - to focus resources on implementing interventions that have positive desired outcomes. Low- and middle-income countries are increasingly looking to build evidence-informed policies and programs, including through global ministerial calls to action on research in 2004 and 2008 (Bamako Call to Action 2008).

Reducing the gap between what is known and what is implemented - the evidence to action gap - has long been a concern of the family planning community (Echols 1974; Freedman and Berelson 1976; Koenig and Whittaker 1991; Seidman and Horn 1991; Foreit and Frejka 1998; Simmons et al. 2002; WHO 2006). The field of family planning was founded on research beginning in the 1950s and 1960s with research-based demonstration projects in Asia showing that family planning could work in reducing fertility and improving health outcomes (Foreit and Frejka 1998). Family planning operations research and implementation science programs were designed to inform improvements in family planning services and programs. In addition to academic research, the family planning field has long benefitted from evidence generated from populationbased surveys, including, for example, national Demographic and Health Surveys and Reproductive Health Surveys, and more recently PMA2020 Surveys.

Yet, in the late 1990s, when developing ExpandNet, a widely used framework for guiding scale up which grew from experience with family planning operations research, Simmons et al. (2007: ix) noted a "growing recognition...that 'data seldom speak for themselves' and that research-based recommendations are rarely sufficient to change practice." This knowledge is reflected in a number of current initiatives seeking to bridge the evidence to action gap by generating and sharing evidence and by creating consensus around global evidence bases. These current initiatives include the Implementing Best Practices Initiative (www.ibpinitiative.org), the family planning High Impact Practices Initiative (www.fphighimpactpractices.org), FP2020's knowledge platform on their website designed for "connecting people, ideas and evidence to inspire, inform and accelerate progress for family planning" to achieve the goal set out at the 2012 London FP Summit to reach 120 new family planning users by 2020 (www.familyplanning2020.org).

Given the rich history of evidence generation and attention to evidence use in family planning, it would be reasonable to assume that the evidence is well used in policy and program decision-making. This paper examines that assumption, focusing specifically on: When is evidence used, what types of evidence are used, and how is evidence used in policy and program decision-making related to family planning. This paper explores researchers' and decision-makers' views of "evidence" and what types of evidence policymakers and program managers seek when facing implementation decisions; how evidence is used in decision-making; and how evidence is situated in relation to other factors that influence decision-making. Drawing on the wider literature on evidence-based medicine and policy and on dissemination and implementation research, along with examples from family planning and other health areas, this paper examines the facilitating factors and challenges to evidence use and lists promising interventions to enhance the contribution of research to decision-making. 


\section{Methodology}

This paper is based on a literature search whose objective was to locate references in health or social science on evidence-based policy, knowledge transfer, translation or utilization, evidence collected from "intervention studies" in family planning programs, and "implementation science" for family planning and reproductive health. The references included non-family planning and reproductive health literature to identify common themes around research utilization across disciplines; however, the focus of this paper is on available family planning literature and the application of these common themes to family planning. The literature search included databases, individual websites, and reviews of bibliographies. The search was conducted in PubMed/MEDLINE, Web of Science, and POPLINE, in addition to snowballing references from bibliographies. References were limited to 2000-2014 in the database searches; snowballing of materials went back to the 1990s, although in some cases earlier materials were incorporated in order to capture earlier literature on research utilization in family planning and seminal literature on research utilization. 


\section{Findings}

\section{RESEARCHERS' AND DECISION-MAKERS' VIEWS OF 'EVIDENCE'}

Although the question of how to define evidence is seemingly simple, the answer is complex and nuanced. The term "evidence" has a different meaning to a decision-maker or practitioner than to a researcher (Sumner et al. 2011; Brownson et al. 2009; Lomas et al. 2005; Lewis 2007). Publications on the use of evidence are mostly written by researchers, and thus the definition of evidence in the literature tends to align with researchers' definitions, namely that evidence means research. Further, this tends to means that the definition of evidence is findings that are derived from peer-reviewed research. Writing about evidence-based policy, Bowen and Zwi (2005: 601), state for example, that evidence is something "usually sought [from research] to show effectiveness ('it works'), show the need for policy action ('it solves a problem'), guide effective implementation ('it can be done'), and show cost-effectiveness ('it is feasible and may even save money')."

The research community differentiates between research, monitoring and evaluation (M\&E) and other types of knowledge (e.g. tacit knowledge or practical experience), and generally places a higher value on research evidence compared to other types of knowledge or information. The research community often places more value on research published in the peer-reviewed literature compared to programmatic research reports in the gray literature. Generally, the predominant preference among the research community is for research evidence that falls within existing hierarchies based on the type and quality of the study rather than the suitability of the methodology for the research question. Although current hierarchies of evidence consider randomized control trials to be the gold standard, efforts are underway to develop more flexible standards of research evidence for reproductive health and family planning programming (STEP UP Research Programme Consortium, 2013; Shelton, 201; Lewis, 2007).

Decision-makers define "evidence" more broadly than many researchers do and often seek a range of evidence, only one of which is research, on which to base decisions. Studies in both developing and developed countries show that decision-makers use a wide array of evidence, including research (both published and unpublished), M\&E (program and local data), government reports and policy documents, community views and complaints, and professional experience, including clinician observations (NabyongaOrem et al. 2014; Armstrong et al. 2014).

Reflecting the needs of decision-makers for a range of evidence, in its 2004 World Report on Knowledge for Better Health, the WHO defined the following types of knowledge (evidence) needed to bring about health systems change: knowledge about priority problems, proven solutions, the implementation context, whether solutions are feasible in local settings and proven mechanisms to bring about change. For decision-makings, having evidence that aligns with these types of knowledge and which fits the local context is important. However, fic research is not always designed to meet the demands for context-specific evidence, which can result in a disconnect between what evidence is generated and what evidence is needed by decision-makings.

\section{HOW EVIDENCE IS USED IN DECISION-MAKING}

Research utilization has been defined for family planning as "making decisions concerning policy, advocacy, and resource allocation, planning and management, and program systems development and strengthening, using information generated from research" (FRONTIERS, ND:1). Evidence is needed for a range of decision-making processes - from policy development to routine program implementation (Trostle 2006). 
To understand how research evidence fits into the policy and program decision-making process, Weiss (1979) defined six models of research utilization that are commonly used: the knowledge-driven model, the problem solving model, the interactive model, the political model, the tactical model, and the enlightenment model. These six models, described in Table 1, offer useful heuristic categories for understanding how evidence is used in decision-making and how evidence relates to other factors that influence policy, program and practice decision-making. These models continue to emerge as major categories of research utilization in studies on evidence use, from using evidence to inform specific decisions, to selective use of evidence to support predetermined policy positions, to tactical requests for evidence to stall decisions and use of evidence by "opposing sides to bolster competing values" (Brownson et al. 2009: 1576). Other materials demonstrate processes where placing value judgments on data or framing evidence is used to satisfy influential decisionmakers; and where evidence is used to inform decision-making about the issue and potential solutions (DFID 2014; Liverani et al. 2013; Freudenberg and Tsui 2014; Sumner et al. 2011).

\section{TABLE 1 | Models of Research Utilization}

\begin{tabular}{|c|c|}
\hline Research Utilization Model & Description of Research Utilization Model \\
\hline Knowledge-driven model & $\begin{array}{l}\text { Linear process that proceeds from basic research to applied research to } \\
\text { product development and application }\end{array}$ \\
\hline Problem solving model & $\begin{array}{l}\text { Policymakers and researchers share and agreeing on a goal and utilizing } \\
\text { existing research or commissioning research to meet this goal }\end{array}$ \\
\hline Interactive model & $\begin{array}{l}\text { Evidence is introduced into "a complicated process that also encompasses } \\
\text { experience, political insight, pressure, social technologies, and judgment" } \\
\text { (Weiss 1979: 429). }\end{array}$ \\
\hline Political model & Stakeholders use research to justify their predetermined positions \\
\hline Tactical model & $\begin{array}{l}\text { Decision-makings cite the need for additional research as a stalling } \\
\text { mechanism in decision-making }\end{array}$ \\
\hline Enlightenment model & $\begin{array}{l}\text { One study or a body of evidence does not directly affect decision-making, } \\
\text { but rather influences stakeholders' views on a topic generally }\end{array}$ \\
\hline
\end{tabular}

Source: Weiss, 1979

Policymaking and program design and implementation are complex processes, and how evidence from research, particularly from individual studies, informs decision-making is also complex and difficult to measure (DFID 2014; Kerner 2008; Trostle et al. 1999). A number of reviews and studies have found that while the idea of using evidence may be positively received by individual decision-makers, evidence from research tends not to be a central factor in the reality of policy and program decision-making (DFID 2014; Hyder et al. 2010). Factors that contribute to or impede the use of evidence from research in decision-making on policies, programs, and practices have changed little over time and are found throughout the policymaking literature and in the scale-up and family planning operations research literature (DFID 2014; Spicer et al. 2014; Oliver et al. 2014; Grimshaw et al. 2012; Clar et al. 2011; Hyder et al. 2010; WHO 2006; Almeida and Basolo 2006; Innvaer et al. 2002; Trostle et al. 1999; Oliver et al. 2014; Koenig and Whittaker 1991; Haaga and Maru 1996; Askew et al. 2002; Simmons et al. 2002; Kim 2006; Simmons et al. 2007; Brambila et al. 2007).

Facilitating factors for using research evidence include using or producing evidence that is aligned with current policy interests; the availability of local data; data on effectiveness; analyses of the feasibility of 
implementing the findings in the health system; community pressure and support for the intervention; support from/involvement of multinational organizations; and good leadership and government support for the use of research evidence. Key barriers to research evidence use include power and budget struggles; high turnover of policy staff; the lack of capacity of governments to use research; and lack of incentives for decision-makers and for researchers to ensure evidence use in decision-making.

Analyses have generally found that research evidence that supports decision-makings' existing beliefs, and that are temporally aligned with current priority issues, are much more likely to be taken up (Brambila et al. 2007). Haaga and Maru (1996: 85) found in Bangladesh that "policy advice [on family planning] that is consonant with existing power relations (between layers of the hierarchy or among functional units) is the easiest to implement." Some evidence suggests that, when used and presented correctly, research can be used to change the minds of decision-makers rather than being used only in an instrumental fashion to support an already held position (Askew et al. 2002; Smith et al. 2015; DFID 2014).

Research evidence is more easily used to define problems than to suggest solutions. One issue on using evidence from research to propose solutions is the complexity of many policies and programs and the lack of clear research evidence on which to base decisions (McCoy et

"Research evidence is more easily used to define problems than to suggest solutions."

al. 2010; Lyons 2010; Kay 2010; Atkinson et al. 2015). Complex health systems issues are not easily amenable to investigations which use strict research designs and thus constitute what are referred to as "wicked problems:" those for which there is no one answer or solution (Churchman 1967; Glasgow et al. 2012). When dealing with wicked problems, being able to identify "which measure was taken, when it was taken, and the degree to which it was pursued, reflects not only the evidence, but very real and complex political and economic pressures at different moments in time" (Harris, 2010: 83). Research on politically sensitive or contentious issues is more difficult to get incorporated into policy and program decision-making (Hill and Hupe 2009).

Researchers' lack of understanding of the policy and program decision-making context has been a longstanding issue in bridging the evidence to action gap-this lack of understanding can affect the research that is conducted and how valuable research evidence is for decision-making (Weiss 1979; Haaga and Maru 1996; Koenig and Whittaker 1991; Lomas 1997; Trostle et al. 1999; Brownson et al. 2009; Sumner et al. 2011; Liverani et al. 2014). This lack of understanding goes the other way as well—many decision-makers may lack a solid understanding of researchers' motivations, methods, and data. In a study of in six countries (Argentina, Egypt, Iran, Malawi, Oman, and Singapore), policymakers noted a range of barriers to the use of research in health decision-making specifically (Hyder et al. 2010). These barriers included poor communication and dissemination of research, policymakers own inability or lack of technical capacity to interpret or understand technical data, and the influences of the ever-changing political context.

Donor priorities can influence country use of research evidence in decision-making, and these priorities may or may not align with national or local priorities. In their review of the political and institutional influences on the use of evidence in public health policy, Liverani et al. (2014: 5) explain that "donors tended to promote interventions with strong evidence bases, but they do so in ways that may neglect local context, needs and capabilities." Donors seek international evidence while national stakeholders prefer local evidence (Nabyonga-Orem and Mujumbi 2015). Donors determine what research they will fund, where they will fund 
it, and who they will fund to carry it out (Eyben 2013; Askew et. al 2002). Donors and multilateral organizations also have a tendency to influence national priorities based on their global agendas (Behague et al. 2009; Behague and Storeng, 2008). For example, the family planning field witnessed a negative natural experiment in the use of research evidence to guide programming during the 1990s, when, despite continued quantification of unmet need for family planning (Cleland et al. 2006), national policymakers and program managers followed the lead of donors in shifting funding to respond to HIV/AIDS.

Researchers often consider themselves to be the 'objective' purveyors of 'the evidence,' and tend to regard the influence of other groups with "vested interests" on the decision-making process as being subjective and non-empirical (Sumner et al. 2011: 8). Yet there is growing realization that researchers have their own values that influence the research they conduct, which has resulted in calls for researchers to acknowledge the values and beliefs that they bring to the research process and their topics (Askew et al. 2002; Eyben et al. 2013; Lyons 2010; Trostle 2006; Sheikh et al. 2014). Writing about family planning and other health areas in Mexico, Trostle et al. (1999: 104) write that "by implying that scientists do not have 'vested interests', and by claiming the moral high ground for science, this perspective can hinder the participation of researchers in policymaking." Claims of scientific "exceptionalism" can not only alienate potential decision-makers, it can also influence whether and how those decision-makers use and implement evidence itself. Futhermore, researchers do not speak with one voice, nor do they necessarily support the same research. These varying vantage points can cause confusion for decision-makings about the value of evidence for decision-making and the credibility of researchers in the process (Askew et al. 2002; Lyons 2010; Eyben et al. 2013).

\section{OTHER FACTORS AFFECTING DECISION-MAKING}

Criticism of the evidence-based medicine and evidence-based policy paradigms suggests that they rest on naïve attempts to base policy and practice on research evidence alone (Crewes and Young 2002; Lewis 2007; Hunsmann 2012; Liverani et al. 2014). While evidence from research should be included in decision-making, there is widespread recognition that it is not - nor should it be - the only factor that decision-makers take into consideration when making decisions. The literature is clear that decision-makers take a range of factors into consideration when making decisions about developing and implementing policies, programs, and practices. In the Handbook for Family Planning

${ }^{6}$ The literature is clear that decision-makers take a range of factors
into consideration when
making decisions."

Research, Fisher et al. recognized that operations research results "are combined with other information (political, experiential, colleague's opinions, other research findings) [and that the new information could be crucial, particularly if it provides decision-makers with the additional confidence they need to make necessary service delivery changes" (Fisher et al. 1991: 66).

Decision-making on policy, program, and practice development and implementation are influenced by other factors including politics, the social, economic, and cultural context of decision-making, and the health service infrastructure (Almeida and Bascolo 2006; Buse et al. 2006; Cookson 2005; Peters et al. 2013; Lomas 1997). In 2006, the WHO sponsored two technical consultations on turning research into practice; these included case studies from sexual and reproductive health research which noted that "linkages between those involved in generating knowledge and those responsible for applying it are inadequate and fragile" (WHO 2006: 8). Researchers and policymakers work under different organizational structures, have different incentives 
driving their work, and operate under different time scales for implementation. Both groups also tend to view each other's work as producing a product (a research study or a policy/program decision) rather than as processes (Lomas 1997) - which can lead to barriers to evidence uptake due to continued misunderstandings about roles and contexts on each side.

Research evidence is filtered through the political environment and other power dynamics that affect the decision-making process (Hunsman 2012; Gleeson et al. 2009; Grindle 2006; Colebatch 2006; Howard 2005; Freudenberg and Tsui 2014). Relationships between decision-makers, researchers, implementers and other stakeholders can also exert influence (Almeida and Bascolo 2006; Askew et al. 2002; Clar et al. 2011), as can power dynamics. In their review of the revision of the Ugandan malaria treatment policy in response to evidence on drug resistance, Nabyonga-Orem et al., (2014) noted that there were a range of stakeholders involved, some of whom played multiple roles in the process with varying levels of support for and influence over the uptake of evidence in the decision-making process to change the policy. Decision-makers need to know if the policy or program they are deciding on is feasible, affordable, and acceptable and "if [not]..., there is little point in adopting it, whatever traditional research evidence says" (Klein 2000 in Locock and Ziebland 2010: 93).

\section{FIGURE 1 | The Role of Evidence and Other Factors in Decision-making}

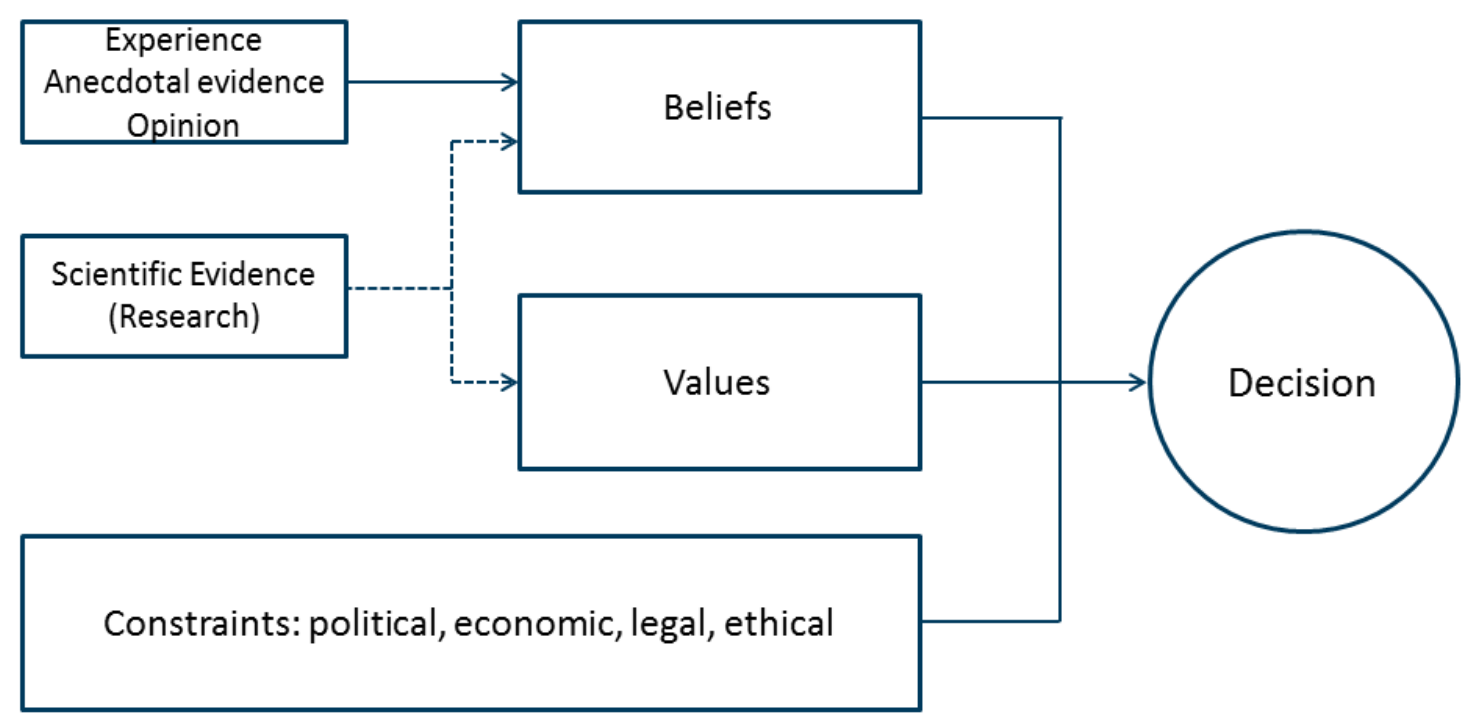

Adapted from Cookson, 2005

Resarcch evidence is generally not the deciding factor in policy formulation or implementation (Kim, 2006; Eyben 2013; DFID, 2014), yet the absence of strong research evidence also "makes it unlikely that government will adopt an innovation" (Spicer et al., 2014; 34). A study of decision-making on family planning that included both decision-makers and advocates in Ethiopia and Kenya found that decision-makers did say that evidence and data, including the costs of implementation, was important to them in decision-making (Smith et al. 2015). However, a Kenyan decision-maker explained that "in policy decisions, there is a tendency to attend to where the concerns are immediate in policymaking" (Smith et al. 2015). Cookson (2005) provides a useful framework of the constellation of factors in addition to scientific evidence that feed into decisionmaking (Figure 1). The framework illustrates that research evidence is filtered through beliefs about the issue at hand, along with anecdotal evidence, experience and opinion, all of which converge to affect the decision- 
making process. Decisions are also affected by individual and group values and are constrained or enabled by political, legal and economic factors.

\section{EXAMPLES FROM FAMILY PLANNING OF OTHER FACTORS INFLUENCING DECISION-MAKING}

The family planning field has numerous examples of factors other than research evidence taking precedence in decision-making. Policymaking and programming for adolescent reproductive health is constrained in many countries by cultural norms that prohibit (at least in theory) sexual activity among that age group, despite evidence that a significant proportion of adolescents are sexually active (UNFPA 2014). Availability of

"The family planning field has numerous examples of factors other than research evidence taking precedence in decision-making." the Standard Days Method (SDM) of contraception is constrained in many countries due to its characterization as a "religious" method and the belief by many physicians and policymakers that, despite 20 years of evidence demonstrating high effectiveness (95 percent with correct use and 88 percent with typical use), there is not sufficient evidence to endorse SDM programming (Wright et al. 2015). Questions about whether SDM is a modern or traditional method, despite the evidence

on its effectiveness, was part of the impetus for a 2015 WHO and USAID-sponsored meeting to define criteria for classification of contraceptive methods.

Task shifting provides another example of how beliefs can affect the interpretation of evidence. The safety and acceptability of nurse and midwife provision of IUDs has been established since the 1970s (Wright et al. 1977; Eren et al. 1983; Lassner et al. 1995), yet in some countries there has been resistance among physician stakeholders. The 2013-2017 Jordanian National Reproductive Health/Family Planning Strategy delineates the need for legislation to allow midwives to insert and remove IUDs. Although the Ministry of Health recently added this function to the job description of midwives, they may only insert IUDs under the supervision of physicians, which greatly reduces midwives' ability to provide IUDs (Higher Population Council 2013). Depo Provera provision in India is another example of how beliefs and political context can constrain the delivery of family planning services. Depo Provera has been blocked from being included in India's public sector family planning program for decades by women's groups who ignore its approval by the WHO and its safe use by millions of women around the world. Entrenched positions can be difficult to dislodge; although mounting evidence over the years can sometimes change decisions, usually this only occurs when evidence is provided in the context of changing norms and societal conditions.

Figure 2 shows a useful schema, adapted from Hill and Hupe 2009, which can be used to assess the dynamic between the scientific (evidence-based) certainty about a topic and the political consensus and contentiousness about the topic. This schema can help researchers understand why a decision may not seem "evidence-based" to them. The more politically contentious a topic is, the more likely the decision will be weighted in favor of factors other than research evidence. As Sumner et al. (2011) point out, family planning and reproductive health are often highly politicized and contentious topics. Sometimes it is easier to "delay decision-making on contentious issues while less contentious topics with clearer, uncontested evidence bases are followed" (Liverani et al. 2014: 6). According to the quadrants, issues for which there are technical agreement (technical certainty) and political agreement, can be considered technical problems for which 
decision-making is relatively straightforward. Many service delivery issues in family planning could fall in this category-for example, when an improved technique for contraceptive provision is studied and adopted into a program. Issues for which there is technical agreement but little political agreement are classified as political problems. Meeting the needs of adolescents for family planning and reproductive health could fall in this category-there is technical certainty that adolescents require sexual and reproductive health services, but there may be political disagreement or political and social taboos against addressing adolescent sexuality. Issues for which there is political agreement but little technical agreement fall into the quadrant of untamed technical problems. An example of this quadrant is the agreement that multiple concurrent partnerships should be addressed in HIV programming, with little agreement or evidence on how to address this issue. Within the four quadrants, the most difficult decisions fall into the quadrant of "wicked problems" - those for which there is little technical certainty and little political agreement on solutions. A current area of discussion in family planning is the focus on gaining new family planning users to reach the FP2020 goal versus focusing on reducing discontinuation among existing users (RamaRao and Jain 2015).

\section{FIGURE 2 | Classifying Decision-making Based on Levels of Political Agreement and Technical Certainty}

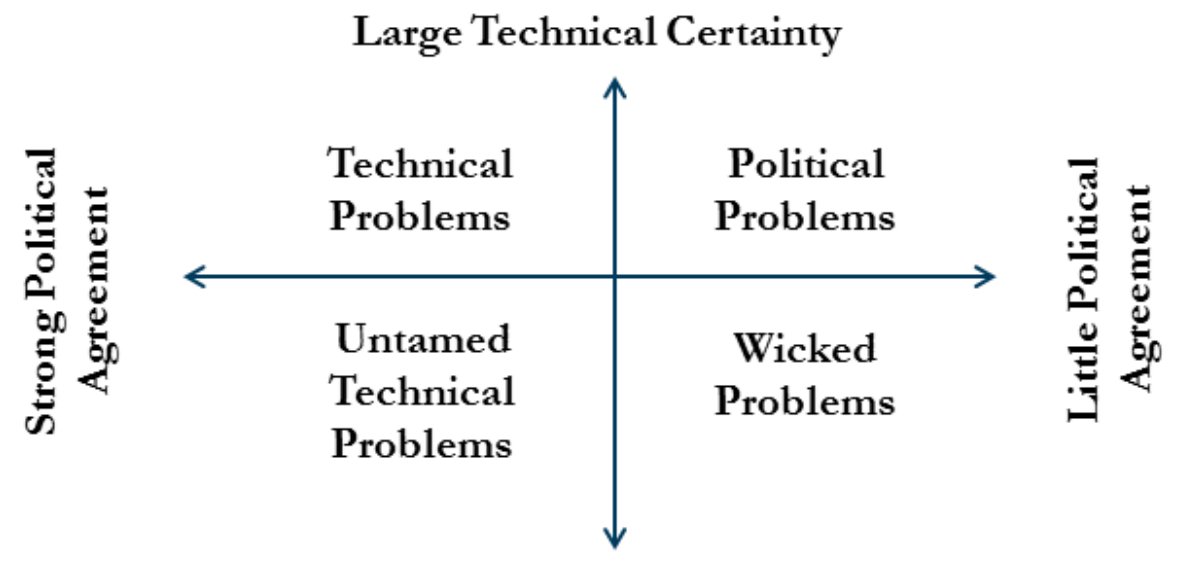

\section{Little Technical Certainty}

Adapted from Hill and Hupe, 2009

Furthermore, evidence that goes against existing programming or that would require significant changes to existing programming can be perceived as threatening to the status quo as its implementation would disturb existing structures, often without additional resources needed to fund the change (Haskins 2015; Alvaro et al. 2010: 2; Kim 2006). The theory of path dependence suggests that incremental changes will be easier to implement than large changes and that those responsible for implementing the changes will interpret the changes to make them fit existing systems and processes, regardless of the evidence (Torfing et al. 2009).

\section{THE IMPORTANCE OF BUILDING EVIDENCE OVER TIME}

It has long been recognized, including in family planning, that single studies rarely change policy or practices (Fisher et al. 1991; Haaga and Maru 1996; Brambila et al. 2007; Smith 2010; Grimshaw et al. 2012; DFID 2014; Isaacson 2014). Reflecting on family planning OR in Guatemala, Brambila et al. (2007: 234) observe that "utilization of research results occurs as a gradual process of information sharing, where researchers 
influence decision-makers through a continual stream of information rather than a single set of findings." Evidence use is often iterative for topics over time (Crewe and Young 2002: 4; McEachran 2006; WHO 2006; Lyons 2010). Thus, it is important to take a long view of the effect of research evidence on policy, program, and practice change. Many examples from family planning illustrate this point. The current focus on task shifting to allow community-based workers to provide injectable contraceptive methods builds on earlier evidence which demonstrated that community-based "...it is important to take a long view of the effect of research evidence on policy, program, and practice change." distribution of family planning was possible (Gallen and Rinehart, 1986; Solo, 1998). Further research to show the safety, acceptability, and feasibility, in addition to the scale up, of community-based distribution of injectables was carried out in Uganda, Madagascar, Kenya, Rwanda, and Nigeria. This research was accompanied by an on-line forum, advocacy, and study tours in order to promote increased research utilization (FHI 2008a; Krueger et al. 2011).

The Balanced Counseling Strategy (BCS) is a family planning counseling tool which is now available in several languages and is widely used in family planning programming. BCS started off as an OR study in Peru to help the Ministry of Health better implement its then new 1999 national norms on family planning (Population Council 2012). The BCS in Peru assisted providers with a job aid which ensured that sufficient time was spent counseling clients on methods suitable for a their reproductive intentions (Leon et al. 2003). The BCS+ adapted the job aid to integrate HIV and STI counseling with family planning and was then tested in South Africa and Kenya (Liambila et al. 2008). Another tool, a checklist to rule out pregnancy, which is available in at least 10 languages and is included in global guidance and has been co-branded by a number of countries, grew from research in the 1990s that "consistently showed that women all over the world were being denied contraception if they were not menstruating when they presented for family planning services" (FHI 2008b).

Emergency contraception (EC) is another example of policy change through an iterative research process; research on post-coital contraception started in the 1970s, with clinical trials of various drug formations of EC in the 1980s and 1990s (Marions 2006). Establishment of the International Consortium of EC, agreements with a pharmaceutical company to market an EC product, the addition of EC to the WHO list of Model Drugs in the 1990s, and, finally, having EC registered as a drug in 96 countries by 2002 was the result of a variety of global, regional, and national evidence demonstrating the effectiveness and safety of EC for use by women (Marions 2006). However, in 2014, Palermo et al. noted the need for additional programmatic research to guide expansion of EC, noting that "since the introduction of dedicated emergency contraceptive pills in the mid-1990s, there has been relatively little research into the success of their introduction and uptake in developing countries" (Palermo et al., 2014).

Family planning studies that examine the scale-up of interventions and practices are usually based on pilot studies, which are often preceded by efficacy and acceptability studies, depending on the intervention being scaled up. The evolution of the Navrongo pilot intervention into the national-level Community-based Health Planning and Services (CHPS) Initiative in Ghana is often cited as an example of successful evidence-based research to policy and program implementation in the family planning community and as "one of a few attempts in Africa to translate findings from a research initiative consisting of several studies into a national health reform programme" (Nyonator et al. 2005). One of the original objectives pursued through both the Navrongo pilot and later scale-up efforts, was to examine whether providing family planning services and 
promoting contraceptive use could "induce and sustain reproductive change" (Phillips et al. 2012). The success of the Navrongo pilot in this regard was not replicated at the national level and the impact on fertility decline after CHPS scale up was reported as negligible. Phillips et al. (2013) attribute this to the lack of transfer to the national scale of the pilot's social network strategy aimed at improving men's attitudes toward family planning, and improving women's autonomy in reproductive decision-making.

While some single studies can influence policy, these examples show that building evidence over time and based on previous findings, with links to policy and program decisions have created effective and widespread scale up in certain contexts. However, the example from CHPS in Ghana shows that even with progressive research, decisions on programming can alter the effect of interventions. To measure the use of any single study in the chain can be difficult, but the effect of bodies of evidence over time can be more evident - and can help identify current research needs to further improve programs.

A review examining the impact of research investments in development provided a strong recommendation that the full body of evidence, including the strength of the evidence and its' suitability for addressing an issue, is examined rather than focusing on individual studies that support already established positions (DFID 2014). DFID cautions that "Funders who wish to fund research to improve evidence-informed policy need to be realistic that direct, attributable policy impacts are relatively rare but that evidence can and does make important contributions to how decision-makers frame issues and to the selection of interventions which have a higher chance of success" (DFID 2014: 43).

\section{PROMISING INTERVENTIONS TO EXPAND THE ROLE OF RESEARCH EVIDENCE IN DECISION-MAKING}

It is unrealistic to assume that research evidence will or should be the only factor which influences decisionmaking. Based on the literature reviewed in this paper, there are five categories of interventions that should be considered to enhance the contribution of research to decisions on family planning policies, programs, and practices: (1) building cultures of evidence use; (2)

"It is unrealistic to assume that research evidence will or should be the only factor which influences decision-making." grounding research in an understanding of the health system and decision-making processes; (3) incorporating research utilization plans into research protocols; (4) strengthening research methodologies for studying complex health systems issues; and (5) studying interventions to increase the use of evidence in decision-making on policies, programs and practices. These types of intervention are explored in more detail in Hardee et al. (2015). 


\section{Conclusion}

Attention to global goals to expand access to family planning has increased focus on ensuring that policy, programming, and practice are "evidence-based," which tends to mean evidence from research. This paper set out to answer when, what types, and how evidence is used in decision-making related to family planning. Despite a rich history of research and interest in using research to improve programs, there is surprisingly scant research on whether and how evidence from research is used in decision-making for development and implementation of family planning programming, policies, and practices. Policymaking, program design, and implementation are complex processes, and understanding how research evidence informs decision-making related to the three is difficult to measure. Adding to the complexity is that researchers and decision-makers define evidence differently, with researchers taking a more narrow view of evidence as findings from research studies while decision-makers include a wider range of information, in addition to research, as evidence, such as M\&E, government reports and policy documents, community views and complaints, and professional experience.

Furthermore, not only does the literature show that decision-makers and researchers have little understanding of, and appreciation for, each other's work environments, neither group have professional incentives to ensure that decisions are evidence-based. Building cultures of evidence that bring decision-makers and researchers together could help increase use of evidence by decision-makers and improve the utility of the evidence produced by researchers. Views of what evidence is need to be more aligned with researchers' understanding that "evidence-based" does not only mean "research evidence-based" to decision-makers and with decision-makers understanding the value of robust research evidence among other evidence they consider when making decisions. Researchers should gain a better understanding of both the context in which they are conducting their research and not only focus on the outcomes of the research, but also on the feasibility of implementation of the findings from the research within the health system and broader country context. Researchers would also benefit from categorizing issues in terms of technical certainty (of the evidence) and political agreement on the issues. Research that addresses areas that are not politically contentious, and for which there is general agreement about the research findings, is more likely to be used in decision-making than research on contentious issues or for which there is not agreement among researchers.

While decision-makers appreciate research, when they make decisions, the research evidence is only one factor they take into consideration - and may not be the most influential factor in their decision-making. This paper has shown that research findings tend to be filtered through decision-makers' values and beliefs in addition to political, economic and social considerations, as they are considered in decision-making. Long established models of research utilization show that research can be used to support pre-established positions, to stall decisions, or to inform general views on topics rather than specific decisions. Examples from family planning reinforce the persistence of other factors affecting decision-making.

Yet, there is cause for optimism on the use of research evidence in decision-making. A number of promising interventions exist to increase how research evidence, vis a vis other factors, can inform decision-making. Understanding the decision-making environment could help make research more relevant to pressing issues faced by decision-makers, more timely related to planning cycles, and more feasible to be implemented within health or other relevant systems. Expecting policy or program change from single studies is mostly unrealistic, but examples from decades of family planning programming shown in this paper illustrate the incremental influence of evidence from research on family planning policies and programs. 


\section{References}

Almeida, C., and E. Bascolo. 2006. Use of research results in policy decision-making, formulation, and implementation: a review of the literature. Cad Saude Publica, 22 Suppl, S7-19; discussion S20-33.

Alvaro, C., R.F Lyons, G. Warner, S.E. Hobfoll, P.J. Martens, R. Labonté, and E.R. Brown. 2010. "Conservation of resources theory and research use in health systems." Implementation Science. 5:79.

Armstrong, R., E. Waters, L. Moore, M. Dobbins, T. Pettman, C. Burns, B. Swinburn, L. Anderson and M. Petticrew. 2014. "Understanding evidence: a statewide survey to explore evidence-informed public health decision-making in a local government setting." Implementation Science 2014, 9:188 doi:10.1186/s13012-014-0188-7.

Askew, I., Z. Matthews and R. Partridge. 2002. Going Beyond Research. A Key Issues Paper Raising Discussion Points Related to Dissemination, Utilization, and Impact of Reproductive and Sexual Health Research. New York: Population Council, FRONTIERS. 25 pp.

Atkinson, J, A. Page, R. Wells, A. Milat, and A. Wilson. 2015. "A Modeling Tool for Policy Analysis to Suport the Design of Efficient and Effective Policy Responses for Complex Public Health Problems." Implementation Science. 10:26. DOI 10.1186/s13012-015-0221-5.

Bamako Call to Action on Research for Health. 2008. http://www.who.int/rpc/news/BAMAKOCALLTOACTIONFinalNov24.pdf

Behague, D., Tawiah, C., Rosato, M., Some, T., and J. Morrison. 2009. Evidence-based policymaking: the implications of globally-applicable research for context-specific problem-solving in developing countries. Soc Sci Med, 69(10), 1539-1546. doi: 10.1016/j.socscimed.2009.08.006

Behague, D. P., and K.T. Storeng. 2008. Collapsing the vertical-horizontal divide: an ethnographic study of evidence-based policymaking in maternal health. Am J Public Health, 98(4), 644-649. doi: 10.2105/ajph.2007.123117

Bowen, S., and A.B. Zwi. 2005. Pathways to "evidence-informed" policy and practice: a framework for action. PLoS Medicine, 2(7), e166. doi: 10.1371/journal.pmed.0020166

Brambila, C., Ottolenghi, E., Marin, C., and J.T. Bertrand. 2007. Getting results used: evidence from reproductive health programmatic research in Guatemala. Health Policy and Planning, 22(4), 234-245. doi: 10.1093/heapol/czm013

Brownson, R. C., Chriqui, J. F., and K. Stamatakis. 2009. Understanding evidence-based public health policy. American Journal of Public Health, 99(9), 1576-1583. doi: 10.2105/ajph.2008.156224

Buse, K., Martin-Hilber, A., Widyantoro, N., and S.J. Hawkes. 2006. Management of the politics of evidencebased sexual and reproductive health policy. Lancet, 368(9552), 2101-2103. doi: 10.1016/S01406736(06)69837-1

Churchman, C.W. 1967. "Wicked Problems.” Management Science. 14(4): B141-B142. 
Clar, C., Campbell, S., Davidson, L., and W. Graham. 2011. What are the effects of interventions to improve the uptake of evidence from health research into policy in low and middle-income countries? (Systematic review) (pp. 107pp): University of Aberdeen (UoA).

Cleland, J., S. Bernstein, A. Ezeh, A. Faundes, A. Glasier, and J. Innis. 2006. "Family Planning: The Unfinished Agenda." Lancet. 386(9549): 1810-1827.Colebatch, HK. 2006. "What Work Makes Policy? Policy Sci. 39: 309-321.

Cookson, R. 2005. Evidence-based policymaking in health care: what it is and what it isn't. Journal of Health Services Research and Policy, 10(2), 118-121. doi: 10.1258/1355819053559083

Crewe, E. and J. Young. 2002. "Bridging Research and Policy: Context, Evidence and Links." ODI Working Paper 173. 24 pages.

DFID. 2014. "What is the evidence on the impact of research on international development?: A DFID Literature Review." UKAID Department for International Development.

Dopson, S. 2010. "Evidence-based Health Care and The Implementation Gap.” In Lyons, R.F. Ed. 2010. Using Evidence: Advances and Debates in Bridging Health Research and Action. Oxford: Atlantic Health Promotion Research Center. Pp. 72-80.

Echols, J. (ed.) 1974. Making Population-Family Planning Research Useful: The Communicator's Contribution. Conference summary report. Honolulu, HI: East-West Communication Institute.

Eyben, R. 2013. Uncovering the Politics of 'Evidence' and 'Results': A Framing Paper for Development Practitioners. Prepared for the Politics of Evidence Conference in Brighton, U.K., April 2013.

Eyben, R., Guijt, I., Roche, C., Shutt, C., and B. Whitty. 2013. The Politics of Evidence Conference Report. Paper presented at the The Big Push Forward, UK. http://bigpushforward.net/wpcontent/uploads/2013/09/BPF-PoE-conference-report.pdf

FHI. 2008a. "Expanding the Community-based Distribution of Injectable Contraceptives in Africa." Case Studies in Research Utilization. Research Triangle Park, NC: FHI (now FHI 360).

FHI. 2008b. "Improving Contraceptive Access with a Simple Job Aid to Help Rule out Pregnancy." Case Studies in Research Utilization. Research Triangle Park, NC: FHI (now FHI 360).

Fisher, A., J. Laing, J.E. Stoeckel, and J.W. Townsend. 1991. Handbook for Family Planning Operations Research Design. Second Edition. New York: Population Council.

Foreit, J.R., and T. Frejka. 1998. Family Planning Operations Research: A Book of Readings. New York: The Population Council.

Freedman, R., and B. Berelson. 1976. "The record of family planning programs," Studies in Family Planning, $7(1): 1-40$.

Freudenberg, N. and E. Tsui. 2014. "Evidence, Power, and Policy Change in Community-based Participatory Research." American Journal of Public Health. 104(1): 11-14. 
FRONTIERS. ND. Legacy Series: Maximizing Utilization of Research . Washington, DC: Population Council.

Gallen, M.E. and W. Rinehart. 1986. “OR findings: Operations research: lessons for policy and programs.” Population Reports. Series J: Family Planning Programs. 1986 May-Jun; (31):813-852.

Glasgow, R.E., L.W. Green, M.V. Taylor, and K.C. Strange. 2012. "An Evidence Triangle for Aligning Science with Policy and Practice.” American Journal of Preventive Medicine. 42(6): 646-654.

Gleeson, D. 2009. Developing Policy Leadership: A Strategic Approach to Strengthening Policy Capacity in the Health Bureaucracy. A thesis submitted in fulfillment of the requirements for the degree of Doctor of philosophy. School of Public Health, La Trobe University, Australia.

Grimshaw, J. M., Eccles, M. P., Lavis, J. N., Hill, S. J., and J.E. Squires. 2012. Knowledge translation of research findings. Implementation Science, 7. doi: 10.1186/1748-5908-7-50

Grindle, M.S. February 2006. "Modernising Town Hall: Capacity Building with a Political Twist." Administration and Development 26(1): 55-69.

Haaga, J.G. and R.M. Maru. 1996. "The Effect of Operations Research on Program Changes in Bangladesh.” Studies in Family Planning. 27(2): 76-87.

Hardee, K., and K. Wright. 2015. "Expanding the Role of Evidence in Family Planning Policy, Program, and Practice Decision-making.” Working Paper. Washington, DC: Population Council, The Evidence Project.

Haskins, R. 2015. “Social Programs That Work.” New York Times. A17.

Higher Population Council. 2013. National Reproductive Health/ Family Planning Strategy 2013-2017. Amman: HPC.

Hill M and P. Hupe. 2009. Implementing Public Policy, 2nd Edition, Los Angeles, CA: Sage.

Howard, C. 2005. “The Policy Cycle: A Model for Post-Machiavellian Policymaking?” The Australian Journal of Public Adminstration. 64(3): 3-13.

Hunsmann, M. 2012. "Limits to Evidence-based Health Policymaking: Policy Hurdles to Structural HIV Prevention in Tanzania." Social Science \& Medicine. doi: 10.1016/j.sosscimed.2012.01.023.

Hyder, A.A., A. Corluka, P.J. Winch, A. El-Shinnawy, H. Ghassany, H. Malekafzali, M.K. Lim, J. MfutsoBengo, E. Segura and A. Ghaffar. 2010. "National Policymakers Speak Out: Are Researchers Giving Them What they Need?” Health Policy and Planning. 26: 73-82.

Innvaer, S., G. Vist, M. Trommald, and A. Oxman. 2002. Health policymakers' perceptions of their use of evidence: a systematic review. Journal of Health Services Research and Policy, 7(4), 239-244. doi: $10.1258 / 135581902320432778$

Kay, J. 2010. Obliquity. London: Penguin Books.

Kerner, J. 2008. "Integrating Research, Practice, and Policy: What we See Depends on Where we Stand." Journal of Public Health Management Practice. 14(2): 193-198. 
Kim, J. 2006. "WHO ProTest Initiative in South Africa: A Utilization Framework Case Study." Chapter in WHO. Department of Reproductive Health and Research. 2006. Turning Research into Practice: Suggested Actions from Case-studies of Sexual and Reproductive Health. Geneva: WHO. Pp. 51-56.

Klein, R. 2000. From evidence-based medicine to evidence-based policy? Journal of Health Services Research and Policy, 5(2), 65-66.

Koenig, M.A. and M. Whittaker. 1991. "Increasing the Application of Operations Research Findings in Public Sector Family Planning Programs: Lessons from the ICDDR,B Extension Project.” In Seidman, M. and M. Horn. 1991. Operations Research: Helping Family Planning Programs Work Better. Wiley Liss, Inc. Pp. 451-460.

Krueger K, A. Akol, P. Wamala, and A. Brunie. 2011. Scaling up Community Provision of Injectables Through the Public Sector in Uganda. Studies in Family Planning. 42: 117-24.

Lassner, K.J., C.H.C. Chen, L.A.J. Kropsch, M.W. Oberle, I.M.N. Lopes, and L. Morris. 1995. "Comparative Study of Safety and Efficacy of IUD Insertions by Physicians and Nursing Personnel in Brazil." Bulletin of $\mathrm{PAHO} 29 \mathrm{~N}$.

Leon, Federico R, et al. 2003. Improving Provider-Client Interactions at Peru MOH Clinics: Extent, Benefit, and Cost. FRONTIERS Final Report. Washington, DC. The Population Council.

Lewis, S. 2007. “Toward a General Theory of Indifference to Research-based Evidence.” Journal of Health Services Research Policy. 12(3): 166-172.

Liambila, W. et al. 2008. Feasibility, Acceptability, Effect and Cost of Integrating Counseling and Testing for HIV within Family Planning Services in Kenya. FRONTIERS Final Report, Washington, DC, Population Council.

Liverani, M., B. Hawkins, and J.O. Parkhurst. 2013. "Political and Institutional Influences on the Use of Evidence in Public Health Policy. A Systematic Review. PlosOne. 8(10): 1-9.

Locock, L. and S. Ziebland. 2010. “Evidence, Patient Experience and Research.” In Lyons, R.F. Ed. 2010. Using Evidence: Advances and Debates in Bridging Health Research and Action. Oxford: Atlantic Health Promotion Research Center. Pp. 91-93.

Lomas, J. 1997. Improving Research Dissemination and Uptake in the Health Sector: Beyond the Sound of One Hand Clapping. McMaster University Centre for Health Economics and Policy Analysis Policy Commentary C97-1, November 1997.

Lomas, J., T. Culyer, C. McCutcheon, L. McAuley, and S. Law. 2005. Conceptualizing and Combining Evidence for Health System Guidance.” Ottawa: Canadian Health Services Research Foundation.

Lyons, R.F. Ed. 2010. Using Evidence: Advances and Debates in Bridging Health Research and Action. Oxford: Atlantic Health Promotion Research Center.

Marions, L. 2006. "Emergency Contraception.” In WHO. Department of Reproductive Health and Research. 2006. Turning Research into Practice: Suggested Actions from Case-studies of Sexual and Reproductive Health. Geneva: WHO. Pp. 71-72. 
McCoy, D., K. Storeng, V. Fillipi, C. Ronsmans, D. Osrin, B. Matthias, O.M. Campbell, R. Wolfe, A. Prost, Z. Hill, A, Costello, K. Azad, C. Mwansambo, and D.S. Manandhar. 2010. "Maternal, neonatal and child health interventions and services: moving from knowledge of what works to systems that deliver." International Health. 2: 87-98.

McEachran, J. 2006. "A Pathway to Promote and Guide the Use of Sexual and Reproductive Health Research on Sensitive Issues in Policy Formulation and Service Programmes." In WHO. Department of Reproductive Health and Research. 2006. Turning Research into Practice: Suggested Actions from Case-studies of Sexual and Reproductive Health. Geneva: WHO.

Nabyonga-Orem, J. and R. Mijumbi. 2015. "Evidence for Informing Health Policy Development in LowIncome Countries (LICs): Perspectives of Policy Actors in Uganda." International Journal of Health Policy Management 4(x): 1-9.

Nabyonga-Orem, J., M. Nanyunja, B. Marchal, B. Criel., and F. Ssengooba. 2014. "The Roles and Influence of Actors in the Uptake of Evidence: The Case of Malaria Treatment Policy Change in Uganda." Implementation Science. 9(150): 1-14.

Nyonator, F. K., Awoonor-Williams, J. K., Phillips, J. F., Jones, T. C., and R.A. Miller. 2005. The Ghana community-based health planning and services initiative for scaling up service delivery innovation. Health Policy and Planning, 20(1), 25-34. doi: 10.1093/heapol/czi003

Oliver, K., Innvar S., Lorenc T., Woodman J., and J. Thomas. 2014. "A Systematic Review of Barriers to and Facilitators of the Use of Evidence by Policymakers.” BMC Health Services Research. 14(2).

Palermo, T., J. Bleck, and E. Westley. 2014. "Knowledge and Use of Emergency Contraception: A Multicountry Analysis." International Perspectives on Sexual and Reproductive Health. 40(2): 79-86.

Peters, D. H., Adam, T., Alonge, O., Agyepong, I. A., \& N. Tran. (2013). Implementation research: what it is and how to do it. British Medical Journal, 347, f6753. doi: 10.1136/bmj.f6753

Phillips, J. F., Jackson, E. F., Bawah, A. A., MacLeod, B., Adongo, P., Baynes, C., and J. Williams. 2012. The long-term fertility impact of the Navrongo project in northern Ghana. Studies in Family Planning, 43(3), 175-190.

Population Council. 2012. The Balanced Counseling Strategy Plus: A Toolkit for Family Planning Service Providers Working in High STI/HIV Prevalence Countries. Trainer's Guide, Second Edition. The Population Council.

RamaRao, S. and A. Jain. 2015. "Aligning Goals, Intents, and Performance Indicators in Family Planning Service Delivery.” Studies in Family Planning 56(1): 97-104.

Seidman, M, and M.C. Horn. 1991. Operations Research: Helping Family Planning Programs Work Better. New York: Wiley-Liss, Inc.

Sheikh, K., A. George, and L. Gilson. 2014. "People-centered Science: Strengthening the Practice of Health Policy and Systems Research.” Health Research Policy and Systems. 12(19): 1-8. 
Shelton, J.D. 2014. Evidence-based Public Health: Not Only Whether it Works but How Can It Be Made to Work Practicably at Scale. Glob Health Sci Prac. 2014, 2(3):253-258.

http://dx.doi.org/10.9745/GHSP-D-14-00066.

Simmons, R.., Brown, J., and M. Diaz. 2002. Facilitating large-scale transitions to quality of care: an idea whose time has come. Studies in Family Planning, 33(1), 61-75.

Simmons, R., Fajans, P., and L. Ghiron. 2007. Scaling up health service delivery: from pilot innovations to policies and programmes (pp. 205pp). Geneva: WHO.

Smith, E., et al. 2015. Evidence for Family Planning Advocacy: An Assessment of Decision-makers' and Advocates' Needs and Strategies in East Africa. Washington, DC: Futures Group, Health Policy Project.

Smith, L. 2010. Cause and Effect. In Lyons, R.F. Ed. 2010. Using Evidence: Advances and Debates in Bridging Health Research and Action. Oxford: Atlantic Health Promotion Research Center. Pp. 8990.

Solo, J., N. Cerulli, R. Miller, I. Askew, and E. Pearlman. 1998. "Strengthening the Utilization of Family Planning Operations Research: Findings from Case Studies in Africa." Unpublished report from the Population Council FRONTIERS Project.

Spicer, N., D. Bhattacharya, R. Dimka, F. Fanta, L. Mangham-Jefferies, J. Schellenberg, A. TamirWoldemariam, G. Walt, and D. Wichremasinghe. 2014. "'Scaling-up is a Craft Not a Science': Catalysing Scale-up of Health Innovations in Ethiopia, India and Nigeria." Social Science and Medicine. 121: 30-38.

STEP UP Research Programme Consortium. 2013. Second Consultation on Developing Standards for Identifying Evidence -based Practices in Reproductive Health. STEP UP Report. New York: The Population Council. 17 pages.

Sumner, A., J. Crichton, S. Theobald, E. Zulu and J. Parkhurst. 2011. "What Shapes Research Impact on Policy? Understanding Research Uptake in Sexual and Reproductive Health Policy Processes in Resource Poor Contexts." Health Research Policy and Systems. 9(Suppl 1):53: 1-10.

Torfing, J. 2009. "Rethinking Path Dependence in Public Policy Research.” Critical Policy Studies. 3(1): 70-83.

Trostle, J. 2006. "Pathways to promote and guide the use of sexual and reproductive health research." WHO. Department of Reproductive Health and Research. 2006. Turning Research into Practice: Suggested Actions from Case-studies of Sexual and Reproductive Health. Geneva: WHO. P. 44.

Trostle, J., M. Bronfman and A. Langer. 1999. "How Researchers Influence Decision-makings? Case Studies from Mexican Policies." Health Policy and Planning. 14(2): 103-114.

UNFPA. 2014. The power of 1.8 billion: Adolescents, youth and the transformation of the future: State of the World's Population 2014.

Weiss, C. 1979. The many meanings of research utilization. Public Administration Review, 39(5), 426-431. 
WHO. 2004. World Report on Knowledge for Better Health: Strengthening Health Systems. Geneva: WHO. $146 \mathrm{pp}$.

WHO. Department of Reproductive Health and Research. 2006. Turning Research into Practice: Suggested Actions from Case-studies of Sexual and Reproductive Health. Geneva: WHO.

Wright, K., H. Iqteit, and K. Hardee. 2015. Standard Days Method of Contraception: Evidence on Use, Implementation, and Scale Up. Washington DC: Population Council, the Evidence Project.

Wright, N.H., C. Sujpluem, A.G. Rosenfield and S. Varakamin. 1977. "Nurse-Midwife Insertion of the Copper T in Thailand: Performance, Acceptance, and Programmatic Effects." Studies in Family Planning 8(9): 237-243.

Yamey, G., and R. Feachem. 2011. Evidence-based policymaking in global health - the payoffs and pitfalls. Evidence Based Medicine, 16(4), 97-99. doi: 10.1136/ebm.2011.100060. 


\section{The Evidence Project}

Population Council

4301 Connecticut Avenue, NW, Suite 280

Washington, DC 20008 USA

tel +12022379400

evidenceproject.popcouncil.org 